\title{
HUBUNGAN TINGKAT PENGETAHUAN HAND HYGIENE DENGAN KEPATUHAN PELAKSANAAN HAND HYGIENE PADA PESERTA PROGRAM PENDIDIKAN PROFESI DOKTER
}

\author{
Anietya Widyanita, Ekorini Listiowati ${ }^{1}$ \\ ${ }^{1}$ Fakultas Kedokteran dan Ilmu Kesehatan, Universitas Muhammadiyah Yogyakarta
}

\begin{abstract}
Prevention and Control Program (PPI) including hospital accreditation assessment. One of the standard phase is hand hygiene. The hands of health care are often contact with the patient and his environment, thus becoming the most common transmission of HAIs. Hand hygiene can reduce HAIs if done with appropriate recommendation. This study was conducted to determine the relationship between the level of knowledge of hand hygiene and hand hygiene compliance implementation. This study was observational analytic with cross sectional approach. Subjects were participants of educational programs in the medical profession with a total sampling technique. Instrument research using questionnaires and observation sheet. Analyzed with descriptive statistics, the average level of knowledge and implementation of hand hygiene compliance in respondents is less. Analysis distribution of respondents by sex, male totaled 17 people and female totaled 14 people, distribution of respondents according to the level of knowledge, less value totaled 29 people (93.5\%) and enough value totaled 2 people (6.5\%), distribution of respondents according to the level of compliance, less value totaled 26 people (83.9\%) and good value totaled 5 people (16.1\%). Analysis using a correlation test, 0.599 correlation value, where $p<0.005$, positively related. This study shows that there is a positive relationship between the level of knowledge of hand hygiene and hand hygiene compliance implementation. The average level of knowledge has less value. The average rate of hand hygiene compliance implementation has less value.
\end{abstract}

Keywords: Knowledge level of hand hygiene-Implementation of hand hygiene compliance

\section{PENDAHULUAN}

Infeksi nosokomial atau yang saat ini lebih dikenal dengan Health-care Associated Infection (HAIs)adalah penyebab paling penting mortalitas dan morbiditas pasien di rumah sakit. Di rumah sakit yang memiliki program pencegahan dan pengendalian infeksi, tingkat infeksi berkurang mendekati $32 \%$. Banyak penyebab dari HAIs, salah satunya terkait dengan proses dan sistem kesehatan, seperti perilaku profesional yang terlibat. Tangan dari petugas kesehatan adalah pembawa mikroorganisme paling umum dari satu pasien ke pasien lain dan dari lingkungan yang tercemar kepada pasien. Hand hygienemerupakan ukuran yang paling penting dalam tindakan pencegahankarena lebih efektif dan biaya rendah, diperkirakan dengan melaksanakan hand hygiene dampak pengurangan terhadap HAIs adalah 50\% (Madrazo M. 2009).
Di Indonesia HAIs mencapai $15,74 \%$ jauh di atas negara maju yang berkisar 4,815,5\% (Firmansyah, T.A. 2007). Di rumah sakit Yogyakarta insidensi terjadi HAIs secara umum sebesar 5,9\% (Marwoto A., Kusnanto H., Handono D. 2007). Sedangkan kejadian infeksi nosokomial yang terjadi di RS PKU Muhammadiyah Yogyakarta, berdasarkan suatu penelitian didapatkan angka kejadian ISK sebanyak $20 \%$ dari 30 pasien. Infeksi saluran kemih (ISK) adalah salah satu HAIs yang paling sering terjadi yaitu sekitar $40 \%$ dari seluruh HAIs yang dapat terjadi di rumah sakit setiap tahunnya (Arisandy. 2013).

Salah satu program keselamatan pasien di RS PKU Muhammadiyah adalah Pelaksanaan Program Pencegahan dan Pengendalian Infeksi (PPI). PPI dulu diawali dengan nama panitia infeksi nosokomial dengan target meliputi pasien, petugas, dan lingkungan rumah sakit. Tahun 2007 panitia 
infeksi nosokomial berubah menjadi PPI dengan sasaran target lebih luas meliputi pasien, petugas medis, lingkungan rumah sakit, pengunjung, praktikan atau mahasiswa, dan masyarakat sekitar. Kegiatan yang telah dilaksanakan PPI RS PKU Muhammadiyah adalah mencuci tangan. Kegiatan ini dilakukan selama triwulan bulan maret, april, mei tahun 2012 dan ditemukan angka kepatuhan hand hygiene dengan nilai $73(<75=$ kepatuhan minimal) (Arfiana, Tim PPI. 2012).

Berdasarkan penelitian yang dilakukan oleh Meila Supeni didapatkan hubungan antara kepatuhan pelaksanaan hand hygiene dengan pertumbuhan bakteri penyebab infeksi nosokomial dengan nilai korelasi 0,327 (Supeni, Meila. 2010). Hand hygiene adalah tindakan yang biasa di lakukan oleh masyarakat dan memiliki manfaat yang cukup besar untuk mencegah terjadinya HAIs. Studi ini bertujuan untuk mengetahui hubungan tingkat pengetahuan hand hygiene dengan kepatuhan pelaksanaan hand hygiene pada peserta program pendidikan profesi dokter di RS PKU Muhammadiyah.

\section{BAHAN DAN CARA}

Penelitian ini adalah penelitian analitik observational dengan pendekatan cross sectional. Populasi dalam penelitian adalah peserta program pendidikan profesi dokter UMY yang berada di RS PKU Muhammadiyah Yogyakarta yang berjumlah 31 orang. Sampel menggunakan total sampling karena populasi dari penelitian ini relatif kecil.

Sebagai kriteria inklusi adalah bersedia menjadi responden dan merupakan peserta program pendidikan profesi dokter UMY yang belajar di RS PKU Muhammadiyah Yogyakarta. Peserta program pendidikan profesi dokter yang cuti, tidak berada di RS PKU Muhammadiyah
Yogyakarta saat pengambilan data, dan yang tidak mengembalikan kuesioner, dikeluarkan dari sampel penelitian.

Sebagai variabel bebas adalah pengetahuan hand hygiene sedang variabel tergantung adalah kepatuhan pelaksanaan hand hygiene. Alat pengumpulan data dalam penelitian dengan menggunakan lembar kuesioner dan observasi.

Penelitian ini telah dilakukan di RS PKU Muhammadiyah Yogyakarta pada bulan Juni sampai dengan Oktober 2013. Sampel merupakan seluruh peserta program pendidikan profesi dokter yang berada di RS PKU Muhammadiyah Yogyakarta yang ada saat pengambilan data berlangsung.

Pelaksanaannya di awali dengan menemui peserta program pendidikan profesi dokter kemudian menjelaskan tujuan penelitian yang akan dilakukan. Setelah itu responden diberikan lembar kuesioner yang di halaman pertama lembar tersebut terdapat lembar informed consent. Jika lembar informed consent tersebut telah diisi lengkap dan disetujui, maka penelitian dilanjutkan dengan observasi pelaksanaan hand hygiene hingga data yang diperlukan pada lembar observasi terpenuhi.

\section{HASIL PENELITIAN}

Hasil penilaian dan pengamatan rata-rata tingkat pengetahuan dan tingkat kepatuhanpelaksanaan hand hygiene pada peserta program pendidikan profesi dokterdiperlihatkan pada Tabel 1. Pada Tabel 1 tampak bahwaratarata tingkat pengetahuan peserta program pendidikan profesi dokter menyatakan kurang danrata-rata tingkat kepatuhan pelaksanaan hand hygienemenyatakan kurang.

Tabel 1. Statistik Deskriptif

\begin{tabular}{cccccc}
\hline Variabel & N & Min & Max & Mean & Keputusan \\
\hline Tingkat pengetahuan $(X)$ & 31 & 1 & 2 & 1,06 & Kurang \\
Kepatuhan pelaksanaan (Y) & 31 & 1 & 3 & 1,32 & Kurang \\
\hline
\end{tabular}

Tabel 2 merupakan tabel frekuensi jenis kelamin. Dapat diketahui bahwa total peserta program pendidikan profesi dokter di RS PKU Muhammadiyah Yogyakarta sebagai responden adalah 31 peserta, dengan jenis kelamin lakilaki ada 17 orang dengan prosentase $54,8 \%$ dan jenis kelamin perempuan ada 14 orangdengan prosentase $45,2 \%$. 
Tabel 2.Distribusi Responden Menurut Jenis kelamin

\begin{tabular}{cccccc}
\hline & & Frequency & Percent & Valid Percent & Cumulative Percent \\
\hline Valid & Laki-laki & 17 & 54.8 & 54.8 & 54.8 \\
& Perempuan & 14 & 45.2 & 45.2 & 100.0 \\
& Total & 31 & 100.0 & 100.0 & \\
\hline
\end{tabular}

Tabel 3 merupakan tabel frekuensi jawaban untuk variabel tingkat pengetahuanhand hygiene. Diketahui dari analisis kuesioner jawaban peserta program pendidikan profesi dokter yang menjawab dengan nilai akhir kurang sebanyak 29 orang dengan prosentase $93,5 \%$ dan jawaban responden dengan nilai akhir cukup sebanyak 2 orang dengan prosentase $6,5 \%$.

Tabel 3. Distribusi Responden Menurut Tingkat pengetahuan

\begin{tabular}{cccccc}
\hline & & Frequency & Percent & Valid Percent & Cumulative Percent \\
\hline \multirow{2}{*}{ Valid } & Kurang & 29 & 93.5 & 93.5 & 93.5 \\
& Cukup & 2 & 6.5 & 6.5 & 100.0 \\
& Total & 31 & 100.0 & 100.0 & \\
\hline
\end{tabular}

Tabel 4 merupakan tabel frekuensi jawaban untuk variabel tingkat kepatuhan pelaksanaan hand hygiene. Dapat diketahui bahwa pada obeservasi tingkat kepatuhan pelaksanaan hand hygiene didapatkan responden dengan nilai akhir kurang sebanyak 26 orang prosentasenya adalah $83,9 \%$, dan pada observasi tingkat kepatuhan pelaksanaan hand hygiene di dapatkan responden dengan nilai akhir baik sebanyak 5 orang prosentasenya adalah $16,1 \%$.

Tabel 4. Distribusi Responden Menurut Tingkat Kepatuhan pelaksanaan

\begin{tabular}{cccccc}
\hline & & Frequency & Percent & Valid Percent & Cumulative Percent \\
\hline \multirow{2}{*}{ Valid } & Kurang & 26 & 83.9 & 83.9 & 83.9 \\
& Cukup & 5 & 16.1 & 16.1 & 100.0 \\
& Total & 31 & 100.0 & 100.0 & \\
\hline
\end{tabular}

Tabel 5 merupakan tabel korelasi. Dari output dapat disimpulkan bahwa tingkat pengetahuan hand hygienememiliki hubungan korelasi ganda yang sedang terhadap tingkat kepatuhan pelaksanaanhand hygienedengan nilai interpretasi hasil koefisien korelasi ganda adalah 0,599 . Sedang nilai signifikansi sebesar 0,000 , dapat disimpulkan ada hubungan yang signifikan antara tingkat pengetahuan hand hygiene dengan kepatuhan pelaksanaan hand hygiene pada peserta program pendidikan profesi dokter di RS PKU Muhammadiyah Yogyakarta.

\section{PEMBAHASAN}

Hasil penelitian menunjukkan bahwa ratarata tingkat pengetahuan responden kurang dengan skala 1,06 dan tingkat kepatuhan pelaksanaan hand hygiene kurang dengan skala 1,32. Total responden pada penelitian berjumlah 31 peserta dengan jenis kelamin laki-laki berjumlah 17 orang prosentasenya adalah $54,8 \%$ dan jenis kelamin perempuan berjumlah 14 orangprosentasenya adalah $45,2 \%$. Hal ini dipengaruhi oleh banyak faktor beberapa di antaranya adalah pengetahuan, kebiasaan setiap individu, dan fasilitas untuk melaksanakan hand hoyiene (Atti, D.C., Ciliento, G., Pomponi, M., Raponi, M., Rinaldi, S., Tozzi, E.A. 2011). Fasilitas yang digunakan untuk melakukan hand hygiene di RS PKU Muhammadiyah sudah tersedia meliputi tempat mencuci tangan dan ALC yang sangat mudah untuk diakses. Kondisi ini sangat mendukung untuk peserta program pendidikan profesi dokter taat terhadap hand hygiene.

Hal ini juga didukung oleh penelitian observasi lainnya yang dilakukan oleh Atrika (2011) menyatakan bahwa tingkat kepatuhan hand hygiene pada residen $21,22 \%$, perawat $31,31 \%$ dan peserta program pendidikan dokter (coass) 21,69\% (Atrika. 2011). Penelitian lain 
dilakukan pada 200 orang pekerja kesehatan mengungkapkan bahwa $89 \%$ menyadari mencuci tangan adalah pencegahan infeksi yang penting, tetapi kepatuhan dalam pelaksanaan mencuci tangan di antara pekerja kesehatan berkisar $16 \%$ dan 81\% (Garber, S.J, Gross, M., \& Slonim, D.A. 2010). Suatu studi mengungkapkan pelaksanaan hand hygiene meningkat setelah intensive promosi hand hygiene, tetapi 6 bulan kemudian pelaksanaan hand hygiene menurun pada level awal sebelum dilaksanakannya program tersebut. Waktu adalah kunci yang menjadi faktor penting penghambat pelaksanaan hand hygiene (Wilson, J. 2006).

Kondisi saat dilakukan observasi, peserta program pendidikan profesi dokter mengabaikan mencuci tangan mereka setelah mereka kontak dengan pasien resiko rendah seperti melakukan pemeriksaan tekanan darah dan membantu pemeriksaan berat badan. Selain itu peserta program pendidikan dokter juga mengabaikan mencuci tangan setelah memegang peralatan yang berkaitan dengan lingkungan disekitar pasien salah satunya adalah catatan medis pasien. Tidak berkontak dengan pasien bukan berarti hand hygiene tidak perlu dilakukan. Tangan dapat terkontaminasi karena sejumlah benda dalam beberapa kasus, dan membahayakan pasien maupun tenaga kesehatan. Benda yang dimaksud seperti pakaian pasien, handuk pasien, tempat tidur pasien, dan catatan klinis (Porche, A.R. 2008).

Hasil analisis terhadap pengetahuan responden tentang hand hygiene melalui kuesioner didapatkan bahwa sebanyak 29 orang dengan prosentase $93,5 \%$ pengetahuannya masih kurang dan jawaban cukup sebanyak 2 orang dengan prosentase $6,5 \%$. Dari analisa hasil jawaban peserta program pendidikan profesi dokter masih banyak yang kategori tingkat pengetahuannya kurang. Melihat dari beberapa jawaban pertanyaan di kuesioner kemungkinan peserta program pendidikan profesi dokter masih kurang mendapatkan informasi tentang hand hygiene seperti dari buku, artikel atau jurnal. Hasil observasi juga terlihat hal ini dipengaruhi oleh kesibukkan peserta program pendidikan profesi dokter.Faktoryang mengakibatkan ketidakpatuhan dalam melaksanakan hand hygiene adalah aktivitas yang terlalu sibuk, pasien yang banyak, mementingkan pasien terlebih dahulu, panduan dan pengetahuan hand hygiene tidak memadai, hand hygiene dapat menggangu hubungan baik dengan pasien, memiliki anggapan resiko rendah untuk mendapatkan infeksi dari pasien, lupa untuk mencuci tangan, tidak ada contoh dari atasan atau seseorang yang lebih senior, meragukan hasil dari pelaksanaan hand hygiene, tidak setuju dengan rekomendasi (Motacki, K., Kapoian, T., O'mara, B.H. 2010).

Hasil analisis hubungan antara kepatuhan melakukan hand hygiene dan tingkat pengetahuan didapatkan $\mathrm{p}=0,000$, berarti ada hubungan antara tingkat pengetahuan dengan kepatuhan pelaksanaan hand hygiene. Sedangkan interpretasi hasil koefisien korelasi ganda antara Tingkat pengetahuan hand hygienedengan kepatuhan pelaksanaanhand hygienememiliki hubungan sedang dengan nilai korelasi ganda 0,599.

Hasil observasi di ruangan didapatkan kepatuhan responden dalam melakukan 6 tahap pelaksanaan hand hygiene sudah baik, tetapi untuk pelaksanaan hand hygiene pada 3 waktu yang harus dilaksanakannya hand hygiene mengacu pada WHO seperti sebelum kontak dengan pasien, setelah kontak dengan pasien, dan setelah kontak dengan lingkungan masih didapatkan kelalaian. Sedangkan untuk tindakan sebelum kontak asepsis dan kontak cairan tubuh tidak dapat dinilai, karena pada saat observasi dilakukan peneliti tidak melihat pelaksanaan kondisi tersebut. Pada saat observasi ditemukan, 14 peserta melaksanakan hand hygiene sebelum kontak dengan pasien, 17 peserta melaksanakan hand hygiene setelah kontak pasien, dan 21 peserta melaksanakan hand hygiene setelah kontak dengan lingkungan. Pada saat dilakukannya observasi seluruh responden melakukan prosedure alternative cuci tangan dengan alkohol based hand rub dan dari hasil observasi penelitian ditemukan bahwa waktu yang digunakan oleh peserta program pendidikan profesi dokter dalam melakukan hand hgyiene berupa prosedure alternative cuci tangan belum sesuai dengan waktu yang direkomendasikan yaitu berkisar 20-30 detik. Namun dalam penelitian ini peneliti tidak menunjukkan waktu yang di gunakan oleh masing-masing peserta program pendidikan dokter. Sedangkan dalam pelaksanaan 6 langkah hand hygiene, dari 31 responden ada 1 responden yang tidak melaksanakan 6 langkah hand hygiene sesuai dengan rekomendasi dari WHO. Faktor kurangnya pengetahuan juga ikut mempengaruhi ketaatan petugas dalam melakukan 
hand hygiene. Selain itu faktor banyaknya pasien dalam waktu yang bersamaan dan aktivitas yang banyak merupakan faktor yang mempengaruhi masih rendahnya tingkat kepatuhan pelaksanaan hand hygiene. Hal ini sangat penting bahwa seluruh petugas pelayanan kesehatan harus mempelajari secara tepat prosedur pelaksanaan hand hygiene dan pada saat kapan hand hygiene dilakukan. Program edukasi perlu dilakukan untuk memberikan penjelasan pentingnya pelaksanaan hand hygiene dan memberikan panduan yang jelas pada situasi apa hand hygiene harus dilakukan (Wilson, J. 2006). Namun, untuk meningkatkan kepatuhan pelaksanaan hand hygiene ada 3 hal yang perlu di ketahui sepenuhnya yaitu pengetahuan, kebiasaan setiap individu, dan fasilitas untuk melaksanakan hand hgyiene.

Dari beberapa hal yang harus diketahui oleh peserta program pendidikan profesi dokter, maka jika dihubungkan dengan kondisi lingkungan dan fasilitas di RS PKU Muhammadiyah Yogyakarta pada saat observasi dilakukan peneliti melihat pelaksanaan hand washing yang dilakukan oleh perawat sebagai contoh dari pelaksanaan hand hygiene di lingkungan rumah sakit. Sedangkan pada saat observasi di poliklinik dapat ditemukan fasilitas untuk melaksanakan hand hygiene yaitu alkohol based hand rub yang berada di depan ruang poli tersebut dan juga terdapat ruangan yang memiliki fasilitas wastafel. Sedangkan pada saat observasi di bangsal yaitu bangsal ibnu sina dan marwah dapat di temukan fasilitas hand hygiene yaitu wastafel untuk pelaksanaan hand washing dan juga dapat ditemukan alkohol based hand rub yang berada di depan bangsal. Secara umum di RS PKU Muhammadiyah Yogyakarta dapat di temukan dengan mudah fasilitas hand hygiene khususnya untuk pelaksanaan alkohol based hand rub. Di RS PKU Muhammadiyah Yogyakarta juga dapat ditemukan spanduk hand hygiene dan prosedure pelaksanaan hand hygiene yang terdapat didekat wastafel. Hal ini penting untuk mendukung kepatuhan pelaksanaan hand hygiene di lingkungan rumah sakit. Motivasi untuk patuh dalam melaksanakan hand hygiene ketika berada dalam ruangan atau aktivitas masih kurang terutama untuk tindakan yang beresiko rendah, meskipun untuk sarana palaksanaan hand hygiene sudah tersedia di ruangan yang sama dan mudah di akses. Hal ini sangat penting bahwa seluruh petugas pelayanan kesehatan harus mempelajari secara tepat prosedur pelaksanaan hand hygiene dan pada saat kapan hand hygiene dilakukan. Program edukasi perlu dilakukan untuk memberikan penjelasan pentingnya pelaksanaan hand hygiene dan memberikan panduan yang jelas pada situasi apa hand hygiene harus dilakukan. Dalam penyempurnaan pelaksanaan hand hygiene pendekatan multimodal harus dilakukan untuk meningkatkan kepatuhan yaitu kebiasaan dari setiap individu, suasana dari institusi, kendala yang terdapat dilingkungan, penggunaan poster untuk mempromosikan hand hygiene, dan manejemen pendukung yang kuat untuk program rumah sakit (Wilson, J. 2006).

\section{KESIMPULAN}

1. Tingkat pengetahuan hand hygiene memiliki hubungan yang sedang terhadap kepatuhan pelaksanaanhand hygiene(nilai korelasi $0,599)$. Sedang nilai signifikansi sebesar 0,000 , karena kurang dari 0,05 maka disimpulkan ada hubungan yang signifikan antara tingkat pengetahuan hand hygiene dengan kepatuhan pelaksanaan hand hygiene.

2. Rata-rata tingkat pengetahuan hand hygiene peserta program pendidikan profesi dokter yang berjumlah 31 peserta adalah 1,06. Rentang skala untuk penilaian hasil responden 1,06 adalah kurang.

3. Rata-rata tingkat kepatuhan pelaksanaan hand hygiene peserta program pendidikan profesi dokter yang berjumlah 31 peserta adalah 1,32. Rentang skala untuk penilaian hasil responden 1,32 adalah kurang.

\section{SARAN}

1. Sebaiknya untuk meningkatan pengetahuan peserta program pendidikan profesi dokter sebelum praktek di rumah sakit yang berhubungan dengan hand hygiene, peserta dapat diberikan kuliah khusus untuk membahas pentingnya pelaksanaan hand hygiene. Kuliah tambahan tersebut untuk memberikan informasi manfaat dan dampak dari pelaksanaan hand hygiene yang penting untuk peserta dan juga lingkungan rumah sakit.

2. Dirumahsakitdalamupayauntukmeningkatkan kepatuhan pelaksanaan hand hygiene khususnya bagi peserta program pendidikan profesi dokter sebaiknya dapat diberikan promosi yang berlangsung secara berkala. 
Promosi ini bertujuan untuk menunjukkan cara pelaksanaan hand hygiene yang tepat dan lebih memotivasi peserta melaksanakan hand hygiene. Sehingga dengan kegiatan promosi yang berulang akan membuat peserta program pendidikan profesi dokter terbiasa melakukan hand hygiene.

3. Setelah mendapatkan kuliah tambahan dan promosi, sebaiknya dilaksanakan evaluasi berkala. Tujuan dari evaluasi berkala untuk melakukan penilaian apakah terdapat peningkatan pengetahuan dan kepatuhan terhadap pelaksanaan hand hygiene pada peserta program pendidikan dokter.

4. Penelitian yang akan dilakukan selanjutnya sebaiknya dapat melakukan penelitian berhubungan dengan faktor-faktor yang dapat meningkatkan kepatuhan pelaksanaan hand hygiene pada peserta program pendidikan profesi dokter.

\section{DAFTAR PUSTAKA}

Arfiana, Tim PPI. 2012. Pencegahan Dan Pengendalian Infeksi. (online), (http://www.rspkujogja. com/, diakses 4 April 2013).

Arisandy. 2013. Hubungan lamanya kateter terpasang dengan kejadian infeksi saluran kemih pada pasien rawat inap di Rumah Sakit Umum Daerah Ulin Banjarmasin Tahun. (online) Karya Tulis Imiah strata satu.

Atrika. 2011. Perbedaan Angka Kepatuhan Cuci Tangan Petugas Kesehatan di RSUP DR. KARIADI Studi di Bangsal Bedah, Anak, Interna, dan ICU.Karya Tulis Imiah strata satu, Universitas Diponogoro
Atti, D.C., Ciliento, G., Pomponi, M., Raponi, M., Rinaldi, S., Tozzi, E.A. 2011. Healthcare Workers' and Parents' Perceptions of Measures for Improving Adherence to Hand-Hygiene. BMC Public Health, 11:466, 1471-2458

Firmansyah, T.A. 2007. Pemeriksaan Bakteri Total Udara Dan Kuman Staphyilococcus Aureus Dalam Ruang Operasi Di Rumah Sakit Umum Daerah Kota Semarang. Karya Tulis Imiah strata satu, Universitas Diponogoro

Garber, S.J, Gross, M., \& Slonim, D.A. 2010. Avoiding Common Nursing Errors. USA: Lippincott Williams \& Wilkins. pp. 247

Madrazo M. 2009. Effectiveness of a training programme to improve hand hygiene compliance in primary healthcare. $B M C$ Public Health., 9:469, 1471-2458

Marwoto A., Kusnanto H., Handono D. 2007. Analisis Kinerja Perawat Dalam Pengendalian Infeksi Nosokomial Di IRNA I RSUP DR. Sardjito. KMPK Universitas Gadjah Mada

Motacki, K., Kapoian, T., O'mara, B.H. 2010. An Ilustrated Guide To Infection Control. New York: Springer Publishing Company

Porche, A.R. 2008. Hand Hygiene: Toolkit For Implementing The Nation Patient Safety Goal. USA: The Joint Commission on Accreditation of Healthcare Organizations

Supeni, Meila. 2010. Hubungan Antara Perilaku Cuci Tangan Perawat Dengan Pertumbuhan Bakteri Aerob Penyebab Infeksi Nosokomial. Karya Tulis Imiah strata satu, Universitas Muhammadiyah Yogyakarta.

Wilson, J. 2006. Infection Control In Clinical Practice. Elsevier Health Sciences 